\title{
Argument structure and morphologically underived nouns in Spanish and English ${ }^{1}$ Antonio Fábregas, UiT
}

\begin{abstract}
One of the main topics on the study of the relationship between argument structure and lexical categories is the proposal that nouns (and adjectives) structurally do not introduce arguments. This proposal is matched by some morphological facts, such as the one that observes that AS-nominals have to carry overt nominalizers. In this paper, we address some previously unexplained counterexamples to this generalization involving cases of morphological conversion relating nouns to verbs. We argue that these cases of conversion have to be divided in two groups, and that there is one class that carries verbal structure, even though the morphological make up does not reflect this directly. We argue that these cases have to be dealt with by using portmanteau exponents that synthetically lexicalize verbal projections and a syntactic nominalizer. In doing so, this article provides evidence in favour of the hypothesis that single exponents can lexicalize series of heads.
\end{abstract}

Keywords: nominals, argument structure, nominalization, conversion, synthetic exponence

\section{Argument structure and grammatical categories}

In the study of argument structure, some proposals have been made with respect to how different lexical categories can introduce arguments. Many different proposals have argued that verbs (and in some cases, prepositions) can introduce arguments syntactically, while, in general, nouns do not have this capacity at a structural level. The list of recent studies that develop this hypothesis is too long to be included here (see, for example, Marantz 1997, Langacker 1999, Hale \& Keyser 2002, Baker 2003 and Samek-Lodovici 2003). In other words: the structure associated with the verb fight is able to introduce syntactically at least an agent DP and a patient DP, but the noun war does not specify a DP as being its agent or its patient. The DP is introduced as a PP or a genitive modifier (Charlie Wilson's war), and the interpretation that it denotes someone that triggers the war or is affected by it is due to the conceptual interpretation that war receives as a noun: its encyclopaedic entry denotes some eventuality, and this allows the modifier to be interpreted as a participant in the eventuality even if it does not occupy a designated syntactic position for this.

This asymmetry between verbs and nouns or adjectives has been discussed in several different accounts. In the lexical-syntax approach of Hale \& Keyser (2002), verbs are heads that select a complement, while nouns are heads that do not take complements or specifiers. Adjectives are categories that semantically require a subject of predication, but they cannot introduce it, and as a result they need to combine parasitically with a category able to select a complement, so that the subject their semantics requires can be introduced structurally in the specifier of that projection (see also Mateu 2002). Similarly, Baker (2003) also treats verbs as the only category able to introduce arguments by itself. Adjectives, in his account, need to combine with a predication phrase in order to have a subject (with associated agreement effects, see Baker 2008). Nouns are defined by identity criteria, completely independent of argument structure. Croft (1991), from a functionalist perspective, makes similar observations whereby nouns are defined without reference to argument structure, and when they carry it, they have to

\footnotetext{
${ }^{1}$ We are gratefull to Kristine Bentzen, Ángel Gallego, Jaume Mateu, Hagit Borer, Peter Svenonius, Isabelle Roy, Artemis Alexiadou and two anonymous Lingua reviewers for useful comments and suggestions to previous versions of this paper. A special acknowledgement goes to Jaume Mateu and Olga Borik for putting together this volume and inviting me to participate in it. All disclaimers apply. The following abbreviations are used in the paper: 3 (third person), ACC (accusative), adz (adjectivalizer), AM (adjectival marker), impf (imperfective past), NM (noun marker), nmz (nominalizer), nom (nominative), pl (plural), sg (singular), subj (subjunctive), $T h V$ (theme vowel), $v b z$ (verbalizer).
} 
be marked by some means. Naturally, the idea is also present in one form or another in traditional or structuralist accounts of language.

One conclusion that follows from these approaches, namely that if a noun has argument structure it has to be inherited from a verb, was present also in Grimshaw's (1990) classic work on nominalizations. Among nouns whose semantic structure is eventive, Grimshaw establishes a crucial distinction between complex event nouns (like examination) and simple event nouns (like war). Only the first class takes argument structure in the strong sense. Grimshaw's proposal is clear: complex event nouns carry argument structure because they are deverbal. It is not the noun that carries the argument structure, but the verb from which the noun has been morphologically derived, so that the nominal 'inherits' this structure from its base. Therefore, examination -related to examine- is a complex event noun, but war-which is not derived from a verb- is a simple event noun, that might be conceptually interpreted as involving notions like agent or patient, but does not introduce them syntactically. Other nouns that conceptually denote events but are not derived from verbs are expected to behave as simple event nouns, and this is confirmed in a first aproximation to the data: funeral, class, conference, storm, earthquake...

One terminological note is in order before we proceed: the term 'result noun' has been used differently by different researchers. In some cases it refers to a nominal that denotes an eventuality, specifically the result state (see Sleeman \& Brito 2010). In other cases, it refers to the nominalizations that denote the output of a process or an element associated to it (Grimshaw 1990: 49); notice that the ambiguity of 'output' here allows for the interpretation that both result states and physical objects that are created by the process are result nouns. To avoid this potential confusion, we will follow the terminology used in Borer (1999): nouns that take argument structure, independently of whether they denote an event or a result state, are called AS-nominals; nouns that do not are called R-nominals, independently of whether conceptually they denote events (like war) or concrete objects (like gift). The generalization is, therefore, that underived nouns should be R-nominals.

The goal of this article is to address a class of nouns in Spanish and English that, prima facie, seem to contradict this general approach to grammatical categories and argument structure, as they do not contain verbal morphology or overt nominalizers, but show evidence of containing argument structure in the syntactic sense, as well as other properties typical of verbs. In the remainder of this section, we introduce a morphological generalization about the marking that a noun with argument structure contains, and we review Borer's (2009a, 2009b, 2012) analysis of this pattern. In $\$ 2$ we introduce a class of Spanish nouns that apparently falsify the generalization. In $\S 3$ we propose an analysis, where we argue that these nouns can be analyzed as the result of using portmanteau exponents in the lexicalization of syntactic structures containing verbal projections.

\subsection{Morphological marking and argument structure: correlations}

One of the merits of Grimshaw's (1990) distinction between complex event nominals -ASnominals in the terminology adopted here- and simple event nominals -a type of R-nominalsis that the two classes have different morphological marking. AS-nominals in English have overt nominalizers. All nouns presented in (1) have a reading as AS-nominals, and they all can be morphologically decomposed into a verbal base (sometimes allomorphic) and a nominalizer suffix, while those in (2) do not come from verbs and do not show overt nominalizers.

$\begin{array}{ll}\text { a. } & \text { class-ific-ation } \\ \text { b. } & \text { invas-ion } \\ \text { c. } & \text { displace-ment } \\ \text { a. } & \text { war } \\ \text { b. } & \text { party } \\ \text { c. } & \text { conference }\end{array}$


This morphological property is matched by the inability of simple event nouns to pass a variety of tests, as pointed out by Grimshaw (1990), Alexiadou (2001) or Borer (2003), among many others. As noted in Williams $(1981,2007)$, even the English nouns whose root can appear as a verb (unlike those in 2) do not behave like AS-nominals if they are not turned into nouns through an overt nominalizer. (3) shows a number of examples of zero nominals and shows that none of them is able to take argument structure or aspectual modifiers in the sense that overtly derived nominals do.
a. $\quad$ *the walk of the dog for three hours
b. $\quad *$ the dance of the fairy for the whole evening
c. $\quad *$ the (gradual) fall of the trees for two hours
d. $\quad *$ the salute of the officers by the subordinates
e. $\quad *$ the import of goods from China in order to bypass ecological regulations.

[Borer 2009b, example (14)]

Borer $(2009,2012)$ argues that, in order to have argument structure, the nominalizations have to be built over a verbal functional projection. In order to turn that functional structure into a noun, a lexical nominalizer has to select that structure; otherwize it could not appear in a nominal context. If English -as an idiosyncratic property- lacks a phonologically null nominalizer, it follows then that only when an overt nominalizer is present can we have both argument structure and a nominalization.

(4a) shows a root combining with a lexical head. In (4b), a root combines with a functional head. In both cases, we obtain a noun, but the two methods are not equivalent: only the first is able to change the grammatical category of the base, if it had one. That is: in (4a) the complement of the nominalizer could be a verbal projection like AspectP, but this is impossible in (4b) because Classifier is a nominal functional head that is incompatible with verbs.

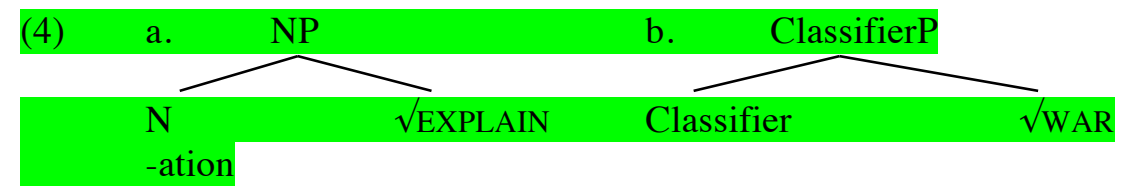

Borer's proposal is that arguments are introduced by functional projections associated to the verbal category -see Borer (2012) for arguments against introducing arguments in V or the root; more specifically, following Borer (2005b), the aspectual projections are responsible for introducing the internal argument. In (5a), the nominal includes aspect and has argument structure; in $(5 b)$, these projections are missing.

(5)

a.

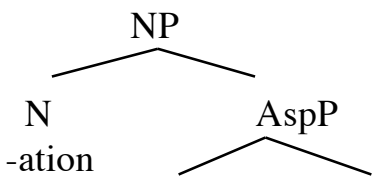




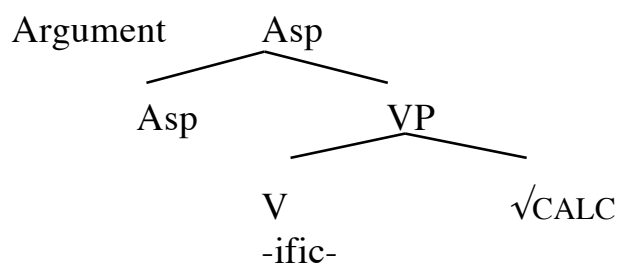

b.

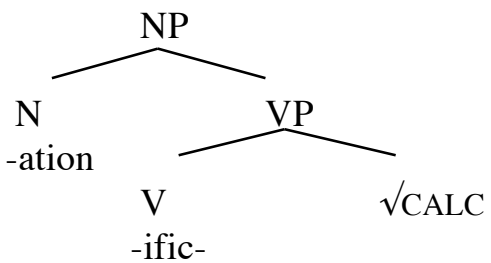

In (5a) we have an AS-nominal, while in (5b) we have an R-nominal.

Now that we have presented the general principles inside Borer's framework, we are in a position to understand her explanation for why zero nominalizations cannot carry arguments. The presence of arguments depends on verbal functional projections. Thus, if we want a base with argument structure we need the structure in (6).

(6)

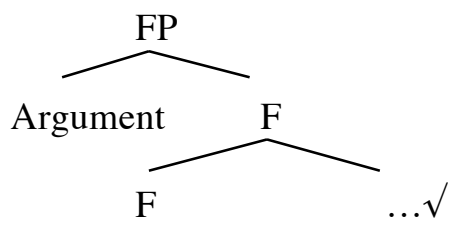

In order to turn (6) into a noun, we need a lexical head like -ation (7a). We cannot use a functional head (7b), because that functional category needs to be compatible with the label of the selected structure, and classifiers (being part of the functional structure of nouns) are not directly combinable with aspect (which belongs to the verbal domain). (7b) is ruled out by a categorical mismatch.
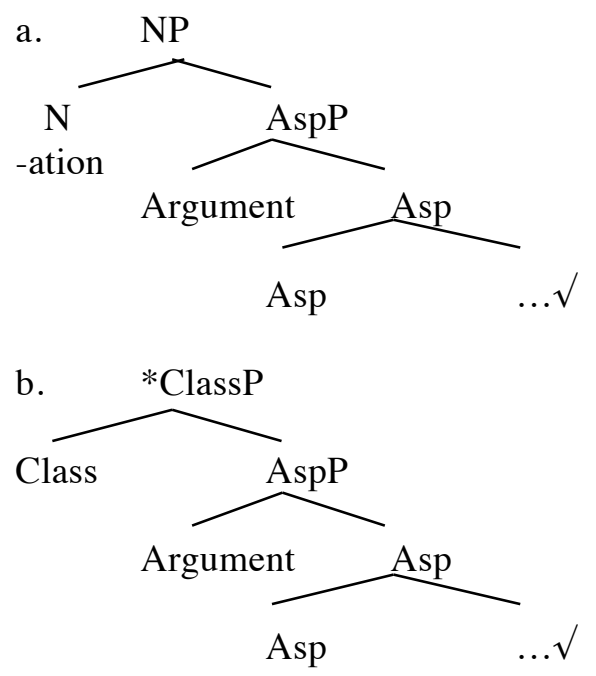

A noun like walk cannot have argument structure because it is turned into a noun by functional projections, not by a lexical functor. Its structure is one in which the nominal projections directly combine with a root that is not dominated by verbal functional projections.

\section{ClassP}




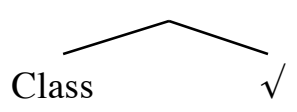

It is crucial to Borer's argument that English does not have a phonologically null lexical nominalizer. If that was the case, the structure underlying the noun walk could be the one in (9), where -in the presence of a lexical functor- nothing prevents the root from being dominated by an FP like AspP, and thus, from having argument structure.

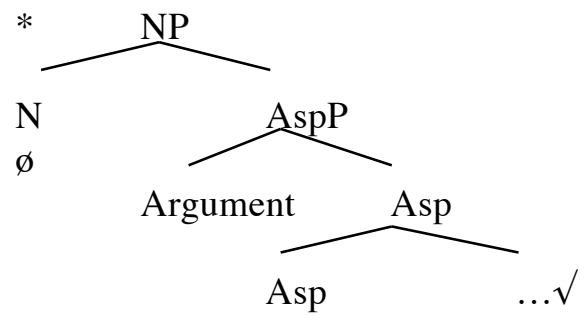

The proposal that English lacks a phonologically null nominalizer is independently confirmed by other data discussed by Borer, so it cannot be dismissed as a stipulation. Crucially, it is not possible to have a zero nominalization of any base that contains an adjectival or verbal lexical functor. ${ }^{2}$

$$
\begin{array}{ll}
\text { a. } & * \text { an atom-ize (vs. an atomization) } \\
\text { b. } & * \text { a ver-ify (vs. a verification) } \\
\text { c. } & * \text { a child-ish } \\
\text { d. } & * \text { a love-ly }
\end{array}
$$

If English had a zero nominalizer, the non-existence of zero nominalizations coming from bases with that morphological shape would be unexpected. This is why: with a zero nominalizer we could obtain nouns from the bases in (10) by adding a nominal lexical functor that is able to revert the lexical category specification of the previous structure (11).

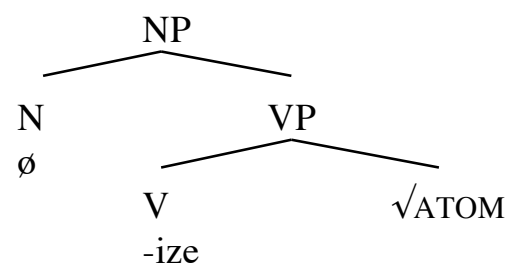

In the absence of this nominalizer, however, Borer correctly predicts that the forms in (10) are impossible. Given their morphological make-up, our only option to turn them into nouns would be to use the functional nominal projections, but these would give rize to a category mismatch, as they dominate a verb.

\footnotetext{
${ }^{2}$ An anonymous reviewer finds as counterexamples nouns like deliverable or delegate, which apparently contain adjectival or verbal affixes. Note, in the case of adjectives, it could be that the affixes spell out a head that is shared by nouns and adjectives, given their close syntactic relation, specially in the case of relational adjectives. In the case of nouns, note that the few counterexamples are of R-nominals that denote participants related to the event denoted by the base. While it could be that we have to relativize the claim, and say that English lacks a phonologically null event nominalizer, it could also be possible that these nominalizations are performed by a null pronominal that is merged in an argument structure position of the verb ([n [delegate]]). There are, however, no cases of event nominals without an overt nominalizer that contain a verbal affix.
} 
(12)

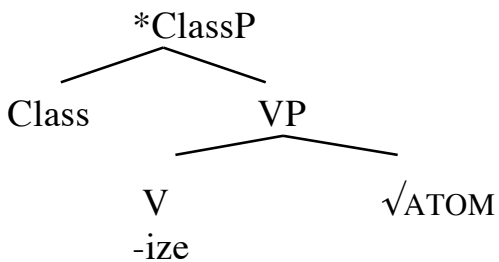

Consequently: if we assume that English lacks a phonologically null lexical nominalizer, we explain why nominals without overt nominalizers cannot carry argument structure: they can only be nominalized by functional heads, which are incompatible with the projection that introduces arguments.

\section{Two classes of verb-related underived nouns in Spanish}

With this background in mind, consider the following two groups of nouns in Spanish.

(13) baja 'sick leave, fall'; conserva 'preserve'; monda 'peel'; obra 'construction work'; tasa 'tax'; baile 'dance'; corte 'cut'; empate 'draw, tie'; empaste 'tooth filling'; pliegue 'fold'; realce 'glamor'; insulto 'insult'; aliño 'salad dressing'; asiento 'seat'; disfraz 'disguize'; regalo 'present'; soplo 'puff, blow'; tiro 'shot'

(14) ayuda 'help'; charla 'chat'; entrega 'delivery'; firma 'signature'; quema 'burn'; siembra 'sowing'; ataque 'attack'; cierre 'closing'; desarme 'disarmament'; rescate 'rescue'; transporte 'transportation'; abandono 'abandonment'; perdón 'amnesty'; envío 'dispatch'; entierro 'burial'; pago 'payment'; chute 'shot'

In both cases, the base involved in these nouns is morphologically related to a verb (15), and there is no overt nominalizer, so these nouns count as cases of zero nominalization.

$$
\begin{aligned}
& \text { a. conserv- } \mathrm{a}_{\mathrm{N}} \\
& \text { preserve-NM } \\
& \text { 'canned food' } \\
& \text { b. ayud-- } \mathrm{a}_{\mathrm{N}} \\
& \text { help-NM } \\
& \text { 'help' }
\end{aligned}
$$

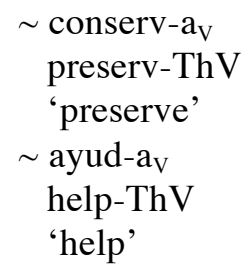

However, the two classes are very different. The nominals in (13) are syntactically built from the root, as Borer's analysis predicts, but those in (14) are built from a verbalized root and include some verbal functional projections. In §2.3-2.6 we will provide a number of formal tests to support this claim. But first, let us show that (13) and (14) are indeed cases of zero nominalizations, that is, that there are no lexical nominalizers in their morphological make up.

We should immediately point out that the data that we report in the following sections reflect the variety of European Spanish spoken in the Center and South of Spain; there are other varieties, such as those spoken in the North-West of Spain, which have different data. We will get back to this case of microparametric variation in our analysis (\$5.2).

\subsection{Conversion with and without category markers}

Conversion is traditionally understood as a process relating two words that share the same root, each one belonging to a different grammatical category, without overt lexical categorizers (16).

$$
\begin{aligned}
& \text { a. }[\text { dance }]_{\mathrm{V}} \\
& \text { b. }[\text { dance }]_{\mathrm{N}}
\end{aligned}
$$


In the standard cases, the change of grammatical category is not matched by any change in the exponents used to spell out the word. In this article we will consider that cases like those in (17), for Spanish, are also cases of conversion despite the presence of a change in the exponents of the word.

$$
\begin{aligned}
& \text { a. abandon-a } \\
& \text { abandon-ThV } \\
& \text { 'abandon' } \\
& \text { b. abandon-o } \\
& \text { abandond-NM } \\
& \text { 'abandonment' }
\end{aligned}
$$

In the first case, the base combines with a theme vowel (ThV), and the result is a verb stem, and in the second case it combines with a noun marker (NM) and the result is a noun stem (cf. Harris 1991, Oltra-Massuet 1999, Oltra-Massuet \& Arregi 2005). In Spanish, there are four noun markers -though it is possible that the last two of them are actually phonological variants of the same one: $-a(18 \mathrm{a}),-o(18 \mathrm{~b}),-e(18 \mathrm{c})$, and $\phi(18 \mathrm{~d}) .^{3}$

$$
\begin{aligned}
& \text { a. mejor-a } \\
& \text { improve-NM } \\
& \text { 'improvement' } \\
& \text { b. abort-o } \\
& \text { abort-NM } \\
& \text { 'abortion' } \\
& \text { c. ataqu-e } \\
& \text { attack-NM } \\
& \text { 'attack' } \\
& \text { d. perdón- } \varnothing \\
& \quad \text { forgive-NM } \\
& \text { 'amnesty' }
\end{aligned}
$$

The theme vowel and the noun marker cannot be treated as lexical categorizers. One crucial difference is that lexical verbalizers can co-occur with theme vowels, and nominalizers or adjectivalizers with noun or adjective markers.

$$
\begin{aligned}
& \text { a. re-al-iz-a } a_{V} \\
& \text { re-al-ize-ThV } \\
& \text { 'make real' } \\
& \text { b. palid-ec-e } \mathrm{e}_{\mathrm{V}} \\
& \text { pale-vbz-ThV } \\
& \text { 'become pale' } \\
& \text { c. fam-os- } \mathrm{O}_{\mathrm{A}} \\
& \text { fame-adz-AM } \\
& \text { 'famous' } \\
& \text { d. mov-i-mient- } \mathrm{O}_{\mathrm{N}} \\
& \text { move-ThV-nmz-NM }
\end{aligned}
$$

\footnotetext{
${ }^{3}$ It would be tempting to treat $-e$ not as a morphological marker, but as an epenthetic vowel: the final consonant in the root is not a licit word final segment in Spanish. However, it is not so clear that we can always treat $-e$ as epenthetic: in words like clas-e 'class-E', the final consonant of the root is a licit segment in word final position, although we could imagine other phonological reasons (eg., having two syllables) for the epenthesis. More research is needed to determine if nouns marked with - $e$ actually have a $ø$ noun marker or carry a different one.
} 
'movement'

If the theme vowel in (19a) and (19b) is responsible for the category change, what is the role of the preceding morpheme?

Note also that ThVs and NMs cannot be used to derive words when there is already an overt morpheme belonging to a different category.
a. chiste $_{\mathrm{N}}>$ joke
b. clase $_{\mathrm{N}}>$
chist-os-o
joke-ous-AM 'funny'
class-ify-ThV 'classify'
$>\quad$ chist-os- $\mathrm{a}_{\mathrm{V}}$
clas-ific-a $\mathrm{a}_{\mathrm{V}}>$
joke-ous-ThV
class
class-ify-NM

An alternative way to avoid this problem would be to not decompose the verbalizers into two distinct exponents, thus not separating $-i z$ - from $-a$. Note, however, that this would make us lose a robust generalization, namely that the exponents used in the verbal paradigm depend on the nature of the final vowel of the stem (see Aronoff 1994, Stump 2001, Blevins 2003 for the relation between markers and subparadigms). The final segment $-a$ in an underived verb like (21a) is relevant to determine what affixes are used, for instance, in the imperfective past or the present subjunctive; if it is $-e$ or $-i$, other forms are used (21b).

$$
\begin{array}{ccc}
\text { a. compr-a } & \sim \text { compr-a-ba } & \sim \text { compr-e } \\
\text { buy-ThV } & \text { buy-ThV-impf } & \text { buy-subj } \\
\text { b. viv-i } & \sim \text { viv-í-a } & \sim \text { viv-a } \\
\text { live-ThV } & \text { live-ThV-impf } & \text { live-subj }
\end{array}
$$

To the same extent that the final vowels determine this allomorphy, when they co-occur with overt verbalizers, the situation is the same. To the best of our knowledge, there are no exceptions to this.

$$
\begin{array}{lcc}
\text { a. clas-ific-a } & \sim \text { clas-ific-a-ba } & \sim \text { clas-ifiqu-e } \\
\text { class-ify-ThV } & \text { class-ify-ThV-impf } & \text { class-ify-subj } \\
\text { b. palid-ec-e } & \sim \text { palid-ec-í-a } & \sim \text { palid-ezc-a } \\
\text { pale-vbz-ThV } & \text { pale-vbz-ThV-impf } & \text { pale-vbz-subj }
\end{array}
$$

\subsection{Directional and non-directional conversion}

One crucial question in the case of conversion is the directionality of the process: in the absence of morphological marking, how can we determine which form is converted from which form? Semantic, syntactic, morphological and phonological factors have been considered in order to determine whether conversion is directional, and if so, which word is used as a base for the other (cf. Marchand 1966, Jackendoff 1975, Clark \& Clark 1979, Lieber 1981, Scalize 1984, Trommelen 1989, Don 1993, 2004, Lieber 2005, among many others).

One observation that comes out of all these works is that what has been descriptively called 'conversion' is likely to correspond to more than one type of process or relation, with cases that show evidence of being directional next to others which have the properties of a non-directional relation. One recent influential approach that captures this distinction inside a constructionist theory is Arad $(2003,2005)$. With semantic, syntactic and phonological evidence, this author shows that in some $\mathrm{V} \sim \mathrm{N}$ conversion cases, the relation is non-directional (23), while in others the verb is derived from the noun (24). Data are taken from Kiparsky (1982).

(23) She anchored the ship with a rock.

(24) *They chained the prisoner with a rope. 
The second verb properly contains the meaning of the corresponding noun chain-forcing that an action of chaining has to be performed with a chain- but the first verb does not contain the meaning of the noun anchor. Arad's proposal is to capture this difference through structural means, and takes advantage of the notion of root as a category-neutral element that only gets assigned to a lexical class once it is dominated in the syntax by a projection containing categorical information (Marantz 1997, 2001; Harley 1995; Embick 2000; Fábregas 2005).

In a case without apparent directionality (anchor), Arad's proposal is that both forms are derived from the same base, the category-neutral root $\sqrt{ }$ ANCHOR. To avoid confusion, we adapt Arad's terminology to Borer's system.

a.

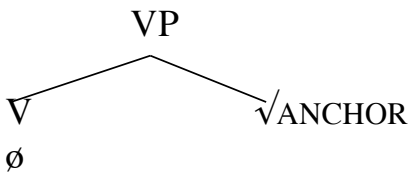

b.

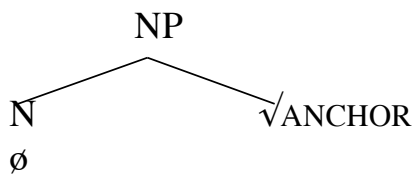

When there is evidence of directionality, Arad proposes that the noun is derived from the root, and the verb is built from that noun.

a.

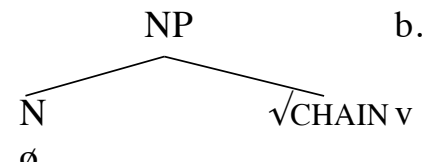

b.

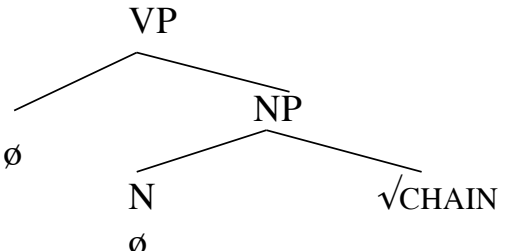

Going back to Spanish, we have seen that (13) and (14) are both cases of conversion. Now we will argue that those in (13) are cases of non-directional conversion -the anchor case- while those in (14) are properly derived from verbs. The next sections show evidence for this distinction.

\subsection{Test 1: argument structure and prepositional marking}

Spanish prepositions are very restricted inside a nominal structure. It can be independently shown that a considerable number of prepositional markers are only licensed if there are verbal or adjectival projections present inside the structure. They can be used, therefore, to diagnose for verbal structure in nominals. If one of these prepositions appears as a noun phrase modifier with a noun like attack, there must be some verbal projection that licenses it. Conversely, if the noun does not allow that preposition, we can conclude that the relevant verbal projections are missing, and therefore, that the structure of the noun has to be similar to that of an R-nominal like book (see Takamine 2010 for an elaboration of the idea that different Ps are licensed by different heads).

The prepositions allowed inside underived NPs are almost exclusively de 'of', con 'with' and $\sin$ 'without' (27).
a. la casa de Marta the house of Marta
'Marta's house'
b. un café con leche
a coffee with milk
'a coffe with milk'
c. una cerveza sin alcohol 


\section{a beer without alcohol}

'a non-alcoholic beer'

In contrast, prepositions that are specialized in introducing the agent of an action or the author of a representation noun (28a), those expressing directions (28b) and the locative preposition en 'in / on / at' (28c) cannot be used with these nouns. The English translation in (28) shows that this is a property by which Spanish clearly contrasts with English.
a. *un libro por Chomsky
a book by Chomsky
'A book by Chomsky'
b. *el puente hacia Brooklyn ${ }^{4}$
the bridge towards Brooklyn
'the bridge to Brooklyn'
c. *la casa en la playa
the house on the beach
'The house on the beach'

In corpora searches, one can find some examples where one of these prepositions co-occurs with a non-derived noun:
a. la guerra contra el narco en México
the war against the narco in Mexico
'the war against the narco in Mexico'
b. la fiesta en el cielo
the party in the heaven
'the party in heaven'

However, syntactic tests show that in these sequences the prepositional phrase is not an internal modifier of the NP. Examples such as those in (29) are grammatical in three situations, which all boil down to the PP being introduced by a predicational structure outside the NP.

In the first case, the PPs are modifiers of a verb (30a). This can be shown by pronominalization: the PPs do not form a syntactic constituent with the noun because this can be pronominalized leaving the PP outside $(30 \mathrm{~b})$. In fact, when the structure is built in such a way that the PP has to be interpreted forcefully as an internal noun modifier (because it forms part of a preverbal subject and there is no focalization), the sentence is ungrammatical (30c).
a. Hay una fiesta en el cielo.
there.is a party in the heaven
'There is a party in heaven'
b. La hay en el cielo.
it-acc there.is in the heaven
'There is that in heaven'
c. *Una fiesta en el cielo tiene muchos invitados.
a party in the heaven has many guests
'a party in heaven has many guests'

The second context where these prepositions co-occur with an underived noun are cases where the PPs are licensed inside a subject NP which gets a propositional reading, that is, where it denotes a state of affairs which involves the noun -as opposed to denoting the individual the NP

\footnotetext{
${ }^{4}$ Although still rejected by many speakers, the preposition hacia is allowed by some with a noun like camino 'road'. However, this noun is related morphologically to the verb caminar 'to walk'.
} 
stands for-. (31a) is possible in a conditional reading ('if there is a party in the Camp Nou, it is well-attended'); evidence that the PP is available only in this kind of reading is found in the fact that if the determiner is definite, blocking a donkey-anaphora reading, the modifier is out (31b).

a. Una fiesta en el Camp Nou siempre es concurrida.

a party in the Camp Nou always is well-attended

'A party in the Camp Nou is always well-attended.

b. *La fiesta en el Camp Nou fue concurrida.

the party in the Camp Nou was well-attended

Intended: 'The party that was in the Camp Nou was well-attended.

The third context is when the PP is a depictive modifier, in which case we assume that the PP is not introduced by the noun, but by a predicational structure that relates it to the noun.

$$
\begin{aligned}
& \text { un hombre en pijama } \\
& \text { a man in pajamas } \\
& \text { 'a man that is in pajamas' }
\end{aligned}
$$

Again, pronominalization provides evidence that the PP in (32) is not internal to the nominal element. In (33a), it can be shown that the segmentation is as we have represented, because the genitive argument can be pronominalized by a possessive leaving behind the PP (33b).
a. una foto [de mi hermano] [en pijama]
a photo of my brother in pajamas
b. su foto en pijama
his photo in pajamas

This suggests that the predication relation between the NP and the PP in (33) is syntactically represented, and instantiated through a functional projection that establishes a subject-predicate configuration. We follow Bowers (1993) and Baker (2003) in their proposal that this projection is a Predication Phrase (PredP), even though we are aware of other options that would work equally well in this example (eg., Den Dikken 2006).

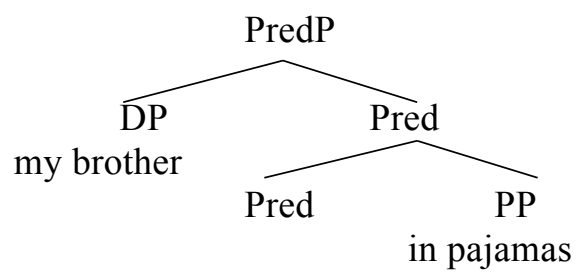

When these interpretations, produced by more complex predicational structures and where the PP is not introduced by the NP, are avoided, the prepositions are ungrammatical. We believe that this provides us with the first strong formal test to determine whether a noun is underived, beyond its semantic interpretation or its morphological marking.

However, we should insist right away that this test only works for languages where prepositions are severely restricted inside non-derived noun phrases, like Spanish. Languages like English allow a much wider range of prepositions to be licensed as noun modifiers even when there is no evidence that the noun comes from a verb. Examples like (35) have been provided by Newmeyer (2009) to deny the proposal that underived nouns do not have argument structure:

(35) a. the anathema by the church of those taking part in satanic rituals

b. America's moratorium on helping to support the UNESCO 
Notice, however, that (as shown above with other cases) English allows these prepositions independently in underived R-nominals. Therefore, their presence in nouns like anathema cannot constitute an argument for the presence of argument structure in these nouns.

Consider from this perspective the initial plausibility of the proposal that the nouns in (14) are derived from verbs. AS-nominals, whose morphological make up shows that they are derived from verbs, license these prepositions in their event reading (36), while nouns underived from verbs reject them (37).

(36) a. la invasión de Grecia por los persas

the invasion of Greece by the Persians

'The invasion of Greece by the Persians'

b. la migración de los pájaros hacia el sur

the migration of the birds towards the south

'The migration of birds towards the south'

c. la explicación de los ejemplos en el aula 2

the explanation of the examples in the class 2

'The explanation of the examples in room 2'

(37) a. *la guerra de Grecia por los persas

the war of Greece by the Persians

b. *la tormenta hacia el norte

the storm towards the north

c. *el análisis de los ejemplos en el aula 2

the analysis of the examples in the class 2

Crucially for our purposes, the nouns in (13) contrast with the nouns in (14) with respect to the prepositions that they allow. Those in (13) act like underived R-nominals (38), while those in (14) act like AS-nominals (39).

(38) a. la baja de María (* por el médico)

the leave of María by the doctor

Intended: 'María's sick leave written by the doctor'

b. el empaste (*en el diente)

the filling in the tooth

Intended: 'the filling that is in the tooth'

c. el tiro del balón (*hacia el portero)

the shot of-the ball towards the goalkeeper

Intended: 'ball shooting to the goalkeeper'

(39) a. el ataque a los servicios públicos por los bancos

the attack to the services public by the banks

'the attack against public services by the banks'

b. el abandono de perros en las gasolineras

the abandonment of dogs in the petrol stations

'the abandonment of dogs in petrol stations'

c. el chute del balón hacia el portero

the shot of-the ball towards the goalkeeper

Intended: 'the shooting of the ball towards the goalkeeper'

\subsection{Test II: aspectual and temporal properties}

A second property of AS-nominals is that they allow modifiers that quantify different sub events or the temporal extension of an event, or express qualities of the way in which the event 
is performed. This property can be shown again if we compare AS-nouns (40) with simple event nouns (41).
a. la invasión de Grecia durante el siglo $\mathrm{V}$
the invasion of Greece during the century $5^{\text {th }}$
'the invasion of Greece during the $5^{\text {th }}$ century'
b. la paulatina explicación de los ejemplos en el aula 2
the gradual explanation of the examples in the class 2
(41) a. *la guerra de Grecia durante el siglo V
'the gradual explanation of the examples in room 2'
b. $\quad$ *el paulatino funeral de los soldados
the gradual funeral of the soldiers

Here, again, we have to be careful about our choice of prepositional phrases. Some R-nominals (42) allow a temporal interpretation of a modifier. In these cases, the only preposition allowed is de -durante and en are out-, and the noun introduced by de, lexically, must already denote a temporal extension, like día 'day', minuto 'minute' or hora 'hour'. The restriction on the preposition used, and the requirement that the noun denotes some time period, suggest that syntactically these are 'normal' noun modifiers whose lexical semantics allows for a temporal interpretation.
a. una guerra de varios años
a war of several years
b. una película de tres horas
a movie of three hours

Once this is controlled for, the picture that we obtain is quite clear: at least in the Central and South European Spanish varieties, the nouns in (13) reject temporal modifiers (43), while those in (14) allow them (44).

a. una baja (*durante dos meses)

a leave during two months

Intended: 'a sick leave that lasts two months'

b. el empaste del diente (*en cinco minutos)

the filling of-the tooth in five minutes

Intended: 'the tooth filling that took five minutes to be completed'

c. la (*paulatina) monda de la manzana the gradual peel of the apple

Intended: 'the gradual peeling of the apple'

(44) a. el ataque a los enemigos durante la noche the attack to the enemies during the night

'the attack against the enemies during the night'

b. la completa quiebra de España en dos años the complete crash of Spain in two years

'Spain's becoming completely bankrupt in two years'

c. el paulatino regreso del español a la enseñanza en Filipinas the gradual return of the Spanish to the teaching in Philippines

'the gradual return of the Spanish language to the Philippines education system'

Consequently, the same nouns that reject specific PPs are also incompatible with temporal and aspectual modifiers. 


\subsection{Test III: evidence for an implicit external argument}

Sichel (2009) analyses existential null pronominals (45), following previous proposals by Condoravdi (1989) and Borer (1998), as referential expressions. As such, Principle C effects force them to take a distinct reference from a preceding referential expression (see Lebeaux 2010 for a recent account of Principle C). This explains that (46), as noted in Borer (1998), is only grammatical if each one of the two existential subjects refers to distinct entities: the embedded pronominal cannot share reference with that of the main clause.

$$
\text { Dafku ba-delet }
$$

knocked.m.pl at.the-door

'Someone knocked at the door' (Lit. 'They knocked at the door')

$$
\begin{aligned}
& \text { Omrim še-potxim et ha-ša'ar be-arba } \\
& \text { say.m.pl that-open.m.pl ACC the-gate at-four } \\
& \text { 'It is said that they are opening the gate at four' }
\end{aligned}
$$

That is, in (46) the sentence is grammatical only if whoever utters it is different from whoever opens the door.

Once this is established, Sichel uses this property of existential null pronominals to show that in some nominalizations the external argument is present (47). In an existential construal, necessarily whoever makes the claim must be distinct from whoever opens the gate.

$$
\begin{aligned}
& \text { Ha-te'ana še-potxim et ha-ša'ar be-arba icbena otanu. } \\
& \text { the-claim that-open.m.pl ACC the-gate at-four annoyed us } \\
& \text { 'The claim that they are opening the gate at four annoyed us'. }
\end{aligned}
$$

Through this test, we can actually check whether our nominals contain verbal structure or not, through the assumption that agents are introduced in one of the verb's functional projections. Again, what we find is a distinction between our two groups of nouns. Those in (13) allow the coreferential interpretation in the existential construal. In (48) it is possible to interpret that the same person (or group of people) that poses the question is the one that eventually would have to pay the debt.

$$
\begin{aligned}
& \text { la pregunta de si deben pagar la deuda } \\
& \text { the question of if must.3pl pay the debt } \\
& \text { 'the question of whether they must pay the debt' }
\end{aligned}
$$

As expected, the noun pregunta 'question' -related to the verb preguntar 'to ask'- is one that does not license the relevant prepositions (49).

$$
\begin{aligned}
& \text { una pregunta económica (*por un periodista) } \\
& \text { a question economic by a journalist } \\
& \text { Intended: 'a question about economy made by a journalist' }
\end{aligned}
$$

In order for the test to work, the semantics of the noun must be propositional, so the test cannot be applied to all members of the class in (13). Other nouns that act in this way are insulto 'insult', cuento 'tale', sospecha 'suspicion' or réplica 'reply', from insultar 'to insult', contar 'to tell', sospechar 'to suspect' and replicar 'to reply'.

On the other hand, the nouns in (14) produce the same kind of effect found in Hebrew by Sichel. In (50), it is ungrammatical to interpret that the same person that makes the plea is the same one that should not pay the debt. 
(50) la súplica de que no paguen la deuda

the plea of that not pay. $3 \mathrm{pl}$ the debt

'the plea that they should not pay the debt'

In order to express the reading where the two subjects are coreferential, an infinitive has to be used.

(51) la súplica de no pagar la deuda

the plea of not to.pay the debt

'the plea not to pay the debt'

Other nouns with the same properties include demanda 'demand', denuncia 'accusation' or perdón 'absolution'. It could be thought that the reason for the impossibility of coreference has to do with an obviation effect, as the subordinate clause is in the subjunctive and it has been noted that some subjunctive subordinate clauses take the main clause as part of their binding domain (Picallo 1985, Kempchinsky 1987, 2009). Note that even in this case it still has to be true that the nominal contains an external argument that triggers the obviation effect. However, it can also be shown that there are similar cases in the indicative.

$$
\begin{aligned}
& \text { la proclama de que no pagan la deuda } \\
& \text { the proclamation of that not pay. } 3 \mathrm{pl} \text { the debt } \\
& \text { 'the proclamation that they do not pay the debt' }
\end{aligned}
$$

Despite the pragmatic plausibility of a scenario where some group declares about themselves that they do not pay the debt, the example in (52) is very difficult to interpret in a coreferential scenario. This is explained if the nominal in (52) contains verbal structure to introduce the implicit agent.

\subsection{Test IV: aspectual prefixes}

A final test to show that the nouns in (14) have verbal structure is that they can combine with aspectual prefixes, that is, prefixes whose meaning operates in the aspectual structure of their bases. No such prefixes are allowed by the nouns in the class (13).

Consider the prefix des- 'dis-'. When attached to nouns unrelated to verbs (53a), this prefix has a privative meaning ('lack of $\mathrm{N}$ '), while when attached to verbal bases it takes a reversative meaning ('undoing the action V') (53b).

$$
\begin{aligned}
& \text { a. des-honor } \\
& \text { dis-honor } \\
& \text { 'dishonor' } \\
& \text { b. des-hacer } \\
& \text { dis-do } \\
& \text { 'undo' }
\end{aligned}
$$

Some of the nominals in (14) can take des-, but always with a reversative meaning: des-arme 'disarmament', des-embarco 'dizembarcation', des-embolso lit. dis-reimburse 'payment', from embolsar 'to give some money to someone'. In contrast, with the nouns in (13), when des- is taken, it has a privative meaning: des-ahogo lit. dis-stress 'relief', des-enfado lit. dis-anger 'ease', des-amparo lit. dis-protection 'helplessness'.

Another relevant prefix is re-. This prefix is rare and non-productive with nouns, but when it does combine with them it has a locative meaning 'behind' (54a). In contrast, with verbs it has a repetition meaning 'doing the action of V again' (54b). 
(54)

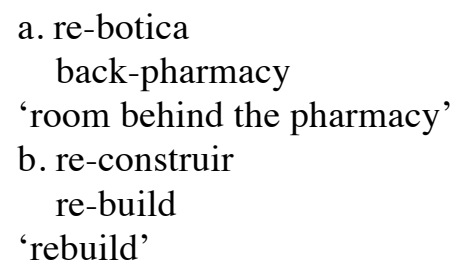

As expected, some nouns in (14) accept this prefix in the iterative meaning: re-conquista 'reconquest', re-arme 'rearmament', re-toque lit. re-touch 'finishing touch to something that had already been manipulated'. We do not find many cases of $r e$ - with the nouns in (13), but in the rare instances this happens the meaning of the prefix could be characterized as one of degree, as in re-celo lit. re-jealousy 'mistrust' or re-cargo lit. re-charge 'surcharge'.

\subsection{Conclusion}

Given the data discussed in this section, it seems that the nouns in (14) correspond to the structure in (55), as they are built from the verbs.

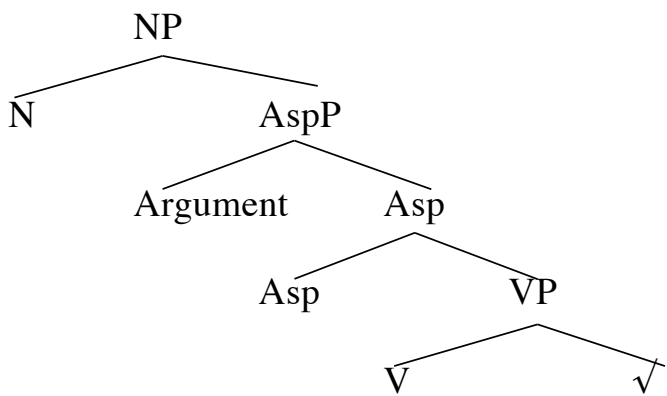

These cases are potentially problematic for Borer's theory if we can show that Spanish, like English, lacks a phonologically null lexical item for event nominalizations. This is indeed the case.

The same facts that showed English does not have a phonologically null lexical nominalizer also apply to Spanish. Verbs with overt verbalizers cannot produce zero nominalizations (56). To obtain nominals from these verbs, overt nominalizers are necessary (57).

$$
\begin{array}{ll}
\text { a. } & \text { *un aterr-iz-o } \\
& \text { a land- } V b-N M \\
\text { b. } & \text { *un palid-ec-e } \\
& \text { a pale- } V b-N M \\
\text { a. } & \text { un aterr-iz-a-j-e } \\
& \text { a land- } V b-T h V-n m z-N M \\
& \text { 'a landing' } \\
\text { b. } & \text { un palid-ec-i-mient-o } \\
& \text { a pale- } V b-T h V-n m z-N M \\
& \text { 'a paling, fading' }
\end{array}
$$

To summarize: there are some nouns in Spanish that contain verbal structure (cf. §2.3-2.6) and are not derived with an overt nominalizer $(\$ 2.1)$. There is evidence that Spanish lacks a lexical zero nominalizer, as in English. Thus, these cases constitute a counterexample to Borer's account of morphological marking in AS-nominals.

Incidentally, there are also problematic cases in English. Borer (2009b) and Newmeyer (2009) mention a variety of cases where English zero nominalizations seem to behave as argument taking nominals, that is, as AS-nominals (58). 
(58) a. my constant change of mentors from 1992-1997

b. the frequent release of the prisoners by the governor

c. the frequent use of sharp tools by underage children

d. an officer's too frequent discharge of a firearm

Borer (2009b), when mentioning these cases, notes that they are not frequent, and suggests that perhaps they could be treated as lexical exceptions. However, in Spanish, it is far from clear that the nouns in (14) are exceptional. For instance, in the Nueva Gramática de la Lengua Española (RAE 2009) more than 350 zero nominalizations are presented, and only around 90 of them must be R-nominals or are preferably used as such. Of course, a serious corpus study would be needed, but impressionistically, this suggests that treating the nouns in (14) as lexical exceptions is unsatisfactory.

Given this puzzle, is it possible to keep the nice isomorphism between morphological makeup and grammatical behaviour in such a way that we explain these cases and integrate them in the theory? And, if so, at what cost? In the next section we will argue in favour of an account of these data which captures the relevant generalizations without making distinctions between kinds of syntactic heads and without positing any kind of zero nominalizer.

\section{An account of silence based on constituency and phrasal spell out}

Let us see where we stand now in terms of data and explanations. We have the following generalizations (a-b) and a set of examples that break the matching between morphology and syntax (c):

a) Overt deverbal nominalizations can be AS-nominals

b) Verbs containing overt verbalizers do not manifest as nominals unless an overt nominalizer is used

c) Some zero nominalizations also behave as AS-nominals

In the next sections, we will argue that the data can be analyzed if we assume that some exponents, like atac- 'attack' can synthetically spell out an ordered series of heads [N, [Asp, [V, $[\sqrt{ }]]]$, that is, spell out as a portmanteau morpheme the nominalization of a verbal stem with argument structure. We will show that, unlike an analysis with a zero nominalizer, this proposal can capture the impossibility of having zero derived nouns that contain verbal affixes.

\subsection{Zero affixes vs.portmanteau morphemes: different predictions}

Assume that after the application of syntactic operations we obtain the structure in (59).

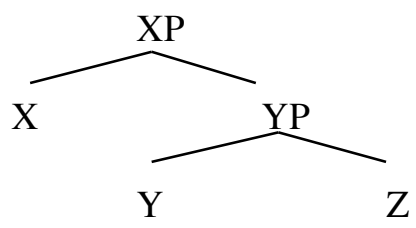

Imagine that the morphological make-up of the structure in (59) is not transparent and it is not possible to identify three distinct morphophonological segments, each one of them corresponding to one of the three heads involved. Assume that there is only one exponent, $<$ blah $>$, materializing the structure.

There are two ways of understanding this mismatch between how many exponents are reflected at PF and how many distinct heads are present in syntax. The first one is that $<$ blah $>$ 
corresponds to one of the three heads (let's say it is $\mathrm{Z}$ ) and both $\mathrm{X}$ and $\mathrm{Y}$ have as their exponents phonologically null morphemes (60).

$(60)$

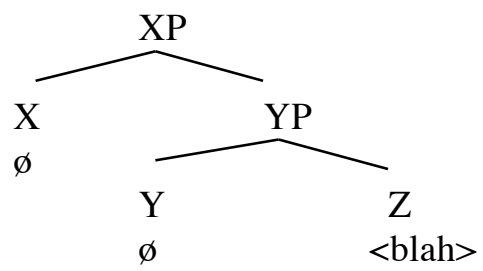

In this scenario, the real segmentation at PF of $<$ blah $>$ would be the one in (61). Of course, the reordering of the zero affixes would not be necessary unless independent tests (like the relative position of adjuncts to $\mathrm{YP}$ ) show that $<$ blah $>$ ends up under $\mathrm{X}$-in other words, it is not obvious that morphophonology would dictate that reordering.

$$
\operatorname{blah}_{\mathrm{Z}}-\emptyset_{\mathrm{Y}}-\emptyset_{\mathrm{X}}
$$

However, there is another possible analysis of the mismatch, namely that the morpheme <blah> is a portmanteau morpheme that spells out all the information contained in the tree in (59) at the same time. That is: $<$ blah $>$ is not the spell out of any of the individual heads, but the spell out of the three of them when they are combined in the order shown in (59). The notation in (62) expresses that $<$ blah $>$ is a morphophonological segment associated to the three positions.

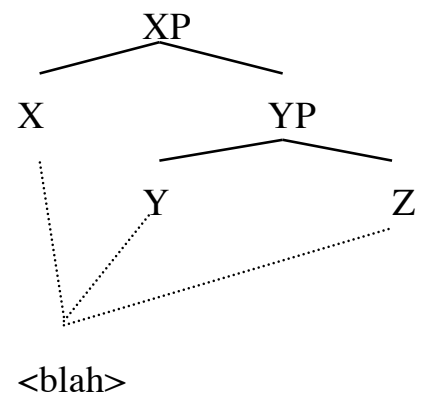

The two analyses make very different predictions. Crucially, the one in (62) forces the three heads involved in the lexical entry of $<$ blah $>$ to form an uninterrupted syntactic constituent. This is so because the morpheme spells out all features -and only those features- contained under the label XP. If there is an additional element between $\mathrm{X}$ and $\mathrm{Y}$ or between $\mathrm{Y}$ and $\mathrm{Z}$, $<$ blah $>$ cannot be used. Also, this approach does not allow the use of $<$ blah $>$ to spell out $X$ and $\mathrm{Z}$ without lexicalising at the same time $\mathrm{Y}$. The reason is that $\mathrm{X}$ and $\mathrm{Z}$ do not form a constituent in the absence of $Y$. Thus, under this analysis $Y$ cannot be lexicalized by another exponent.

In contrast, the proposal in (61) does not make any of these predictions, because there each one of the heads is being lexicalized independently of the others, so the heads do not have to form any constituent to be spelled out. We therefore expect that in (61) additional heads could appear between $\mathrm{Z}$ and $\mathrm{Y}$ or between $\mathrm{Y}$ and $\mathrm{X}$, or that (if for instance there is a process of agreement) $\mathrm{Y}$ could be spelled out by an exponent different from zero without influencing the spell out of $Z$ and $\mathrm{X}^{5}$

\footnotetext{
${ }^{5}$ Note that an approach where single exponents lexicalize series of heads strongly suggests a late insertion approach to spell out, that is, an approach where morphophonological exponents are introduced after the syntactic derivation has been completed. If single morphemes correspond to series of heads, the late insertion of material almost follows logically, because the syntactic derivation has to be complete before the lexical derivation can evaluate which exponents are compatible with it (see Halle 1992, 1997,
} 


\subsection{Lexicalization of syntactic constituents 1: AS-nominals without overt nominalizers}

The generalization in (b), about the impossibility of words like economize being used as nouns unless an overt nominalizer is present, prevents us from using an analysis based on zero morphemes, but not from using an analysis based on portmanteau morphemes. Let us see why.

(63) is the syntactic structure of an AS-nominal.

(63)

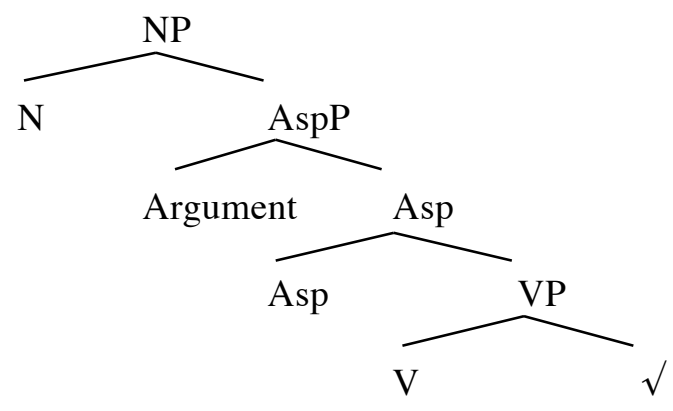

All AS-nominals, including the zero derived nominals in (14), have this syntactic structure. The differences emerge when the exponents are introduced to lexicalize the structure in (63). The possible and impossible morphological make-ups derive from conditions on spell out, and in particular from the need of the relevant morphemes to only spell out heads that form a syntactic constituent in the absence of other heads.

Let us first analyse the case of a zero nominalization that shows evidence of containing verbal structure, as attack or the Spanish equivalent $\operatorname{ataqu}(e)$. We propose that an exponent like attack (or ataqu- in Spanish) spells out as a portmanteau morpheme the phrasal syntactic constituent in (64). ${ }^{6}$

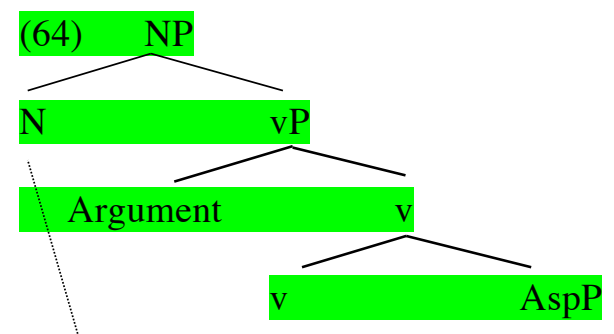

Halle \& Marantz 1993, Embick 2000, Noyer 1997, Fábregas 2009, for additional arguments and discussion about late insertion).

${ }^{6} \mathrm{We}$ assume that at the point at which the lexicalization of the structure happens, the argument in the specifier of AspP has displaced to the position for case assignment, with the result that this lower copy is invisible for spell out, following common assumptions about the phonological representation of multiple copies. Thus, for spell out the argument does not interfere with the constituent lexicalized by the exponent. 


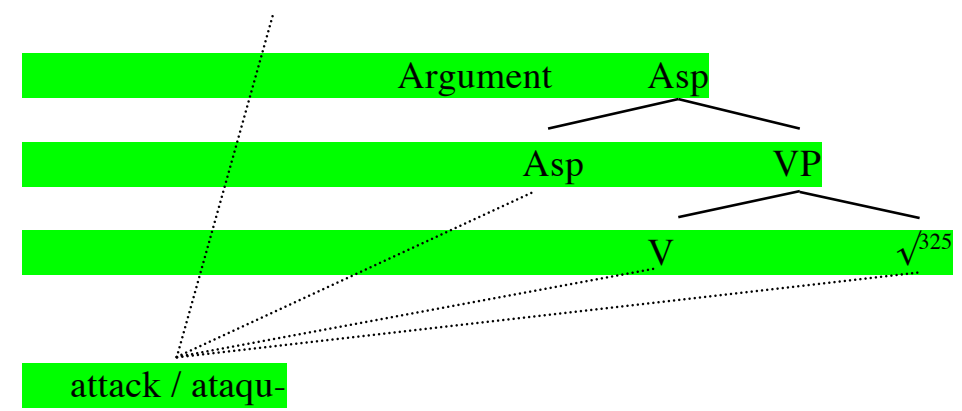

We assume with Borer (2009a, 2009b, 2012) and Acquaviva (2009) that roots introduce phonological indexes (here ' $325^{\prime}$ '), which we interpret as pointers to specific entries in the languages lexical inventory. This is what determines ultimately what lexical exponent will be used: depending on the pointer the root contains, one entry or another will be accessed, and with that, the set of morphosyntactic features that the exponent can maximally lexicalize.

That is: the exponent attack / ataqu- spells out a root, that carries a phonological index, dominated by a $\mathrm{V}$, that is in turn dominated by Asp -introducing the internal argument-, $\mathrm{v}-$ introducing the external argument ${ }^{7}$ and $\mathrm{N}$. Its lexical entry, minimally, should be the one in (65). In this representation, we ignore the conceptual information that is associated to the exponent. In order to spell out this series of heads, as represented in (65), they must form a syntactic constituent, and they must appear in the hierarchical order shown in the lexical entry.

$$
\text { /atak-/ <---> [N [Asp [V [ } \left.\left.\left.\left[\sqrt{ }^{325}\right]\right]\right]\right]
$$

Having the phonological index inside the lexical entry of the exponent implies, in a sense, that the insertion of 'roots' is deterministic: /atak-/, and no other root, can be used in this context. This is, of course, different from what has been claimed in Distributed Morphology, where a distinction is made between functional morphemes (f-morphemes) and lexical morphemes or roots (1-morphemes) (cf. Harley \& Noyer 1998); the insertion of the former, but not of the latter, is deterministic. However, once we allow for phrasal spell out, the distinction between 1- and fmorphemes is blurred: the exponent /atak-/ does not only spell out a root, but also a set of formal features.

Consider, for completeness, the entry of a noun like súplic(a) 'plea'-remember that evidence that the noun introduces an external argument was provided in $\S 2.5-$.

(66)

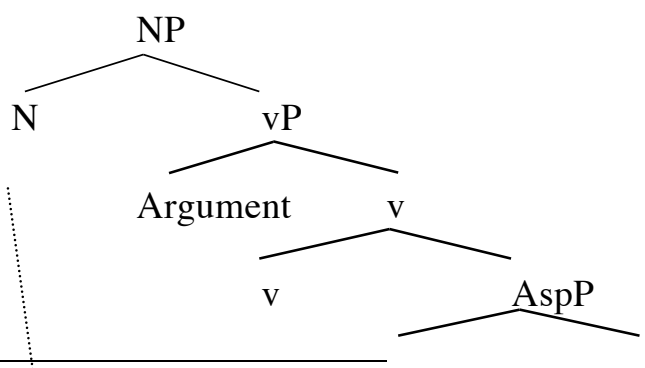

${ }^{7}$ Evidence that attack / atac-involves, even in the nominalization, an external argument could not be provided in $\$ 2.5$., because the noun does not introduce a proposition. However, other tests suggest this is the case. For instance, it does license a final clause:

(i) el ataque a los enemigos para conquistar la ciudad the attack to the enemies to conquer the city 


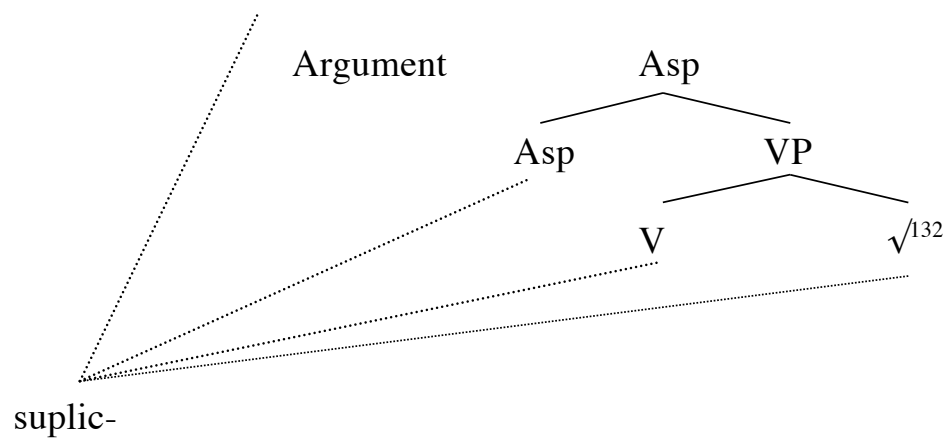

\subsection{The exponent in a verbal context: The Superset Principle}

One relevant question is how the lexicalization takes place in the verbal form, when there is no nominalizer involved. We illustrate this with the case of súplica 'plea'. The relevant tree would be the one in (67).

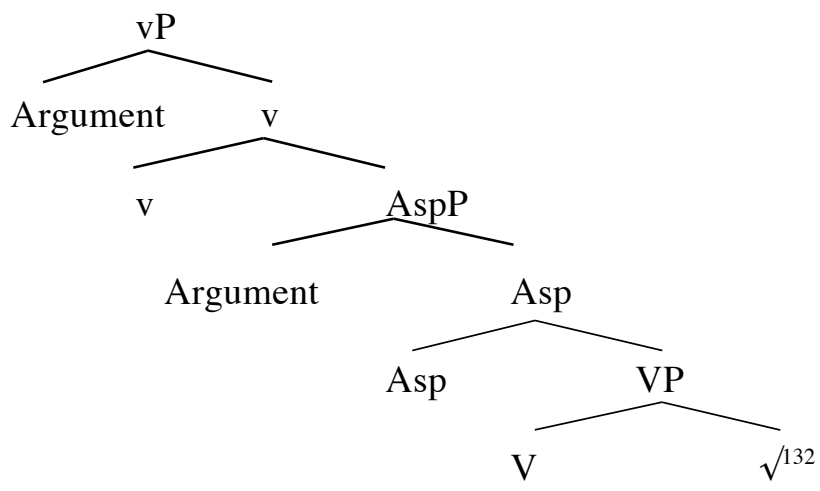

The lexical entry of the exponent suplic- in our proposal is the one in (68). It can be seen that there is a mismatch between the features contained in the lexical entry and those present in the syntax. More specifically, the lexical entry has one feature more than the tree, namely $\mathrm{N}$-for convenience, here we represent the tree associated to the exponent in bracket format-

\section{(68) $\quad$ suplic- $<-->[N[\mathrm{v}[\operatorname{Asp}[\mathrm{V}[\sqrt{ }]]]]]$}

What we want to capture is the fact that the same lexical exponent is able to lexicalize two syntactically distinct -though related- representations, one of which does not correspond straightforwardly to its lexical entry. This is a standard case of syncretism. Recently, Caha (2009: 55, 2010) has argued that syncretism is decided on the basis of the principle in (69), the Superset Principle.

(69) The Superset Principle (Starke 2005): A phonological exponent is introduced into a node if its lexical entry has a (sub)constituent that is identical to the node (ignoring traces).

What this means is that a lexical exponent is able to lexicalize a structure identical to its lexical representation or to a subset of the features represented there, provided that they form a syntactic constituent. Thus, a lexical item can lexicalize a tree that lacks part of the features represented in its entry. An Elsewhere Principle limits this possibility: the syncretism only happens when the lexicon lacks another entry that corresponds more closely to the syntactic tree. For instance, with this device Caha explains the syncretism between nominative and accusative in the Greek fifth declension class (70), where the marker is $-o$. 

a. vun-o
mountain-nom
b. vun-o
mountain-acc

He proposes that the representation of (71a) corresponds to nominative, and the one in (71b) to accusative; that is; accusative is structurally more complex and has one more feature than nominative.

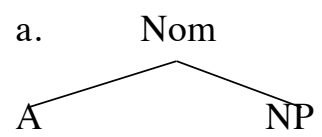

b.

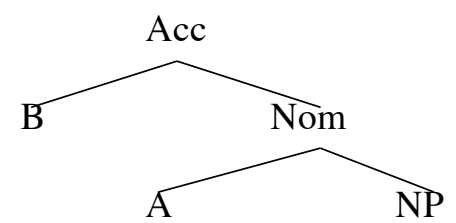

The lexical entry of -o would be the one in (72). By the Superset Principle, this allows it to lexicalize accusative, but also nominative. As the $\mathrm{V}$ class lacks an exponent for nominative, the Elsewhere Principle does not prevent -o from lexicalising nominative, despite the feature mismatch.

\section{$-0<->[B[A]]$}

We use the same procedure to explain the syncretism between súplica 'plea' and suplicar 'to implore'. Even though the lexical entry of suplic- contains a feature [N], there is no other lexical item in the Spanish inventory to lexicalize the tree corresponding to the verbal manifestation that lacks a nominalizer in the tree that has root 132 at its lower node. Consequently, the tree in (67) can be lexicalized by the exponent, as in (73).

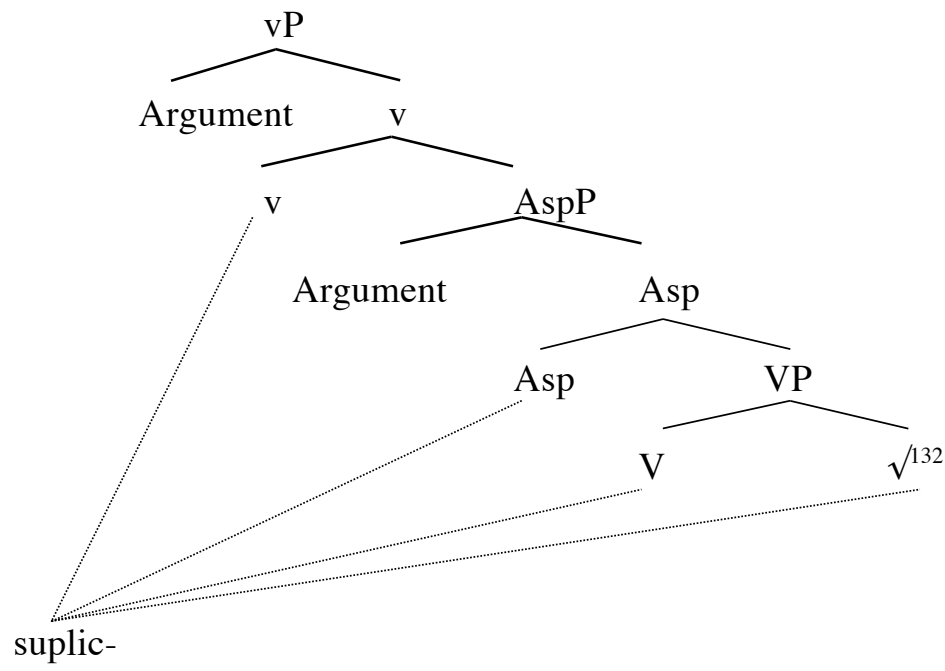

\subsection{Lexicalization of syntactic constituents: $R$-nominals}

What differentiates these examples from nominals like walk in English or those in (13) for Spanish, where there is no internal verbal structure? Any grammatical theory has to introduce some arbitrariness into the lexicon; at the very least this is reflected in the choice of which morphosyntactic features each lexical item spells out. Thus this is an arbitrary matter, and as such there would be other morphemes, such as walk, that are unable to spell out the nominalizer head, because they would lack this feature in their entry. This means that the structure of (74), 
when the root is the one that leads to the lexical entry for walk, will require an extra exponent in order to be spelled out.

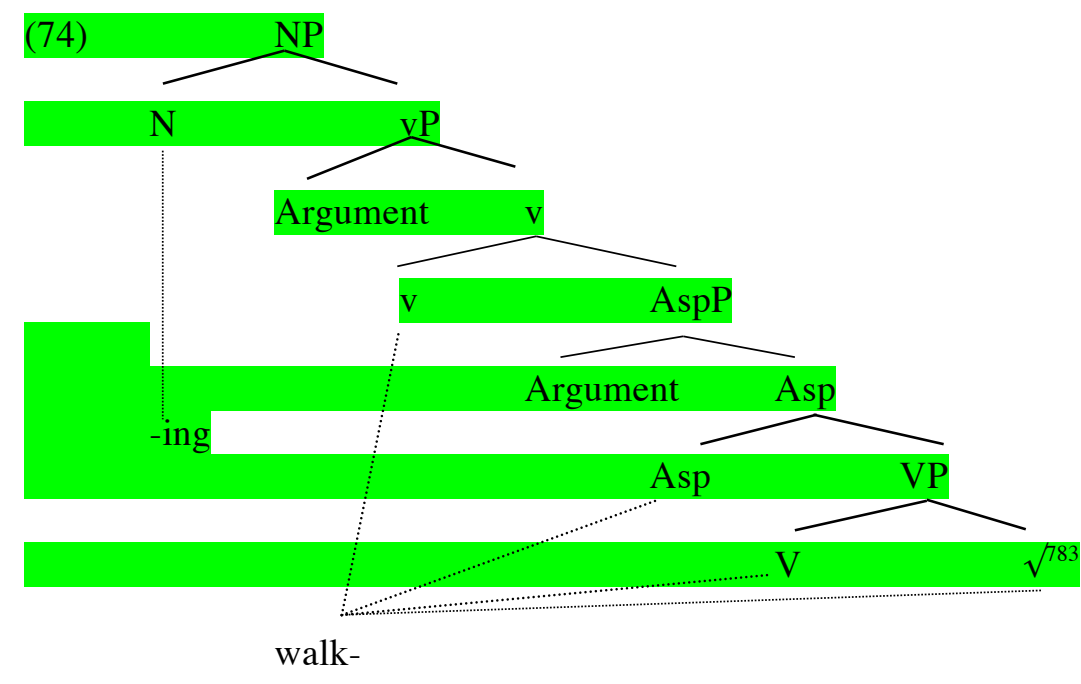

walk <--> [v [Asp [V [ $]]]]]$

In the absence of an $\mathrm{N}$, walk will be able to spell out, alone, the whole structure, but then the whole will behave as a verb.

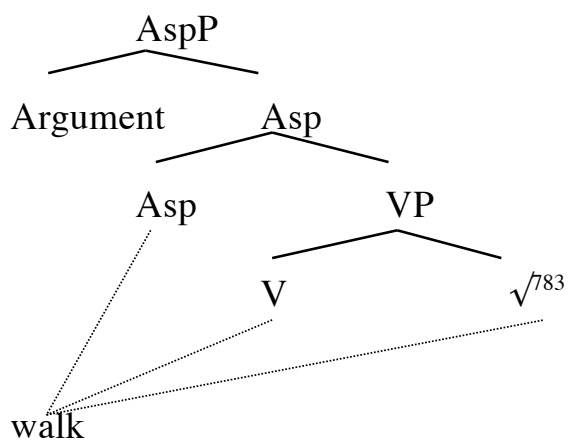

Given the superset principle, we expect the item walk to be able to spell out only the root. When dominated by a Classifier or any other functional projection of a nominal nature, this will turn the root into a noun without overt nominalizers.

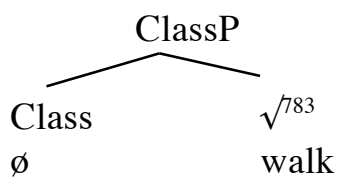

Let us be very clear that the exact set of morphemes that would behave like walk (and therefore will be unable to spell out the constituent formed by the root, verbal structure and a nominalizer), versus those that behave like attack, is not predictable inside a grammar. This will have to be determined idiosyncratically for individual lexical items, as is always the case when determining which features one exponent will spell out in each language. This part of our analysis is 'lexical' in the sense that there are no deeper grammatical principles that determine which morpheme will be able to spell out four heads and which one will only spell out three heads. 
In fact, one of the predictions associated with this approach is that there will be variation in the acceptability of some zero nouns as AS-nominals, insofar as the lexical entries of individual exponents in different varieties of a language can vary,. This prediction is confirmed. In the North-East varieties of Spanish spoken in Catalonia, our informants have pointed out to us that they do not accept a form like ataque 'attack' as an AS-nominal. This result is not surprising. It means that for the speakers of these varieties the lexical entry of ataqu- is like the one for insult'insult' or any other of the nouns in (13), or English walk, thus making it impossible for them to use it to spell out a verbal structure containing a nominalizer.

$$
\text { a. ataqu- (in Central and Southern European Spanish) }
$$

\section{ataqu- <--> $[\mathrm{N}[\mathrm{v}[\operatorname{Asp}[\mathrm{V}[\sqrt{ }]]]]]]$}

b. ataqu- (in Catalonian Spanish)

$$
\text { ataqu- <--> }[\text { Asp }[\mathrm{v}[\mathrm{V}[\sqrt{ }]]]]
$$

Also, in the same way that individual speakers might have slightly different lexical entries for individual exponents corresponding to non-functional categories, we also expect that in some cases the judgements might vary from one speaker to another.

Finally, consider, for completeness, the lexical entry of an exponent like war. Like walk, it is not an AS-nominal; but unlike walk, it cannot be built as a verb, unless overt affixes are used. The two properties are captured if its lexical entry is the one in (78): a root dominated by the functional projection Class.

$$
\text { war }<--->\left[\text { Class }\left[\sqrt{ }^{423}\right]\right]
$$

This prevents the exponent materialising as a verb, and given the set of heads it expresses, it cannot carry argument structure.

\subsection{Why are explicit verbalizers out?}

In order to see more specifically how our proposal does not make the wrong predictions that an account with a zero nominalizer makes, let us now see how the analysis gives an account of the fact that overt verbalizers cannot be contained inside zero derived nominalizations. For that to happen, we need to start from a structure like (79), where we have already introduced an exponent under V (the overt verbalizer).

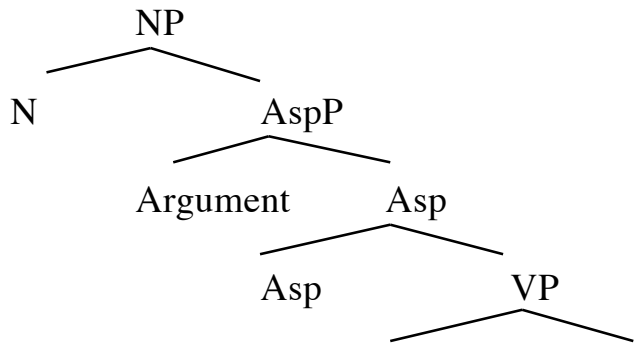




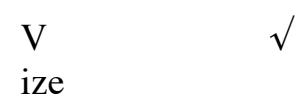

Given (79), no single lexical item will be able to spell out the root, Asp and the nominalizer. The reason is that, once $\mathrm{V}$ is spelled out, the remaining heads do not form a syntactic constituent. Necessarily, then, the root and the nominalizer will have to be spelled out by distinct exponents, as in (80). This explains that economize will never surface as a noun unless a nominalizer is used. We assume -ize will also spell out Asp, as it is almost systematically associated to a particular aspectual class of verbs (change of state). The exponent economwould only spell out a root (with phonological index 666); note that it always needs some additional exponent to spell out as a noun (econom-y) or an adjective (econom-ic).

(80)

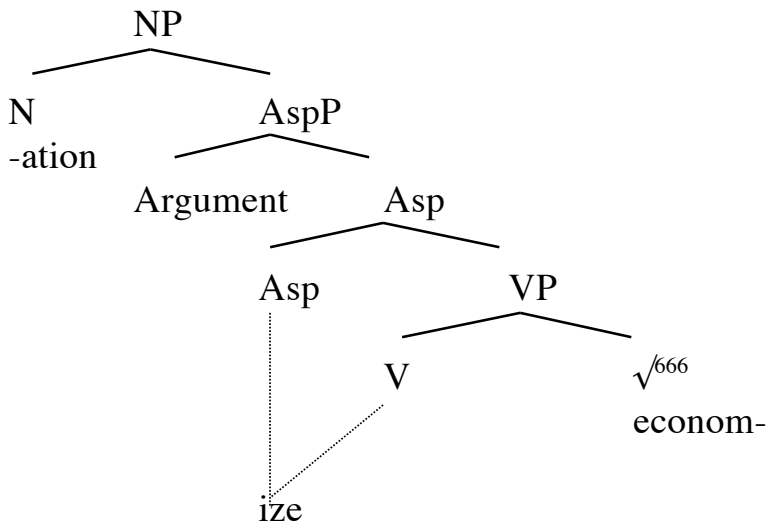

Finally, consider what happens for a root like war, whose lexical entry was already presented in (78).

$(81)$

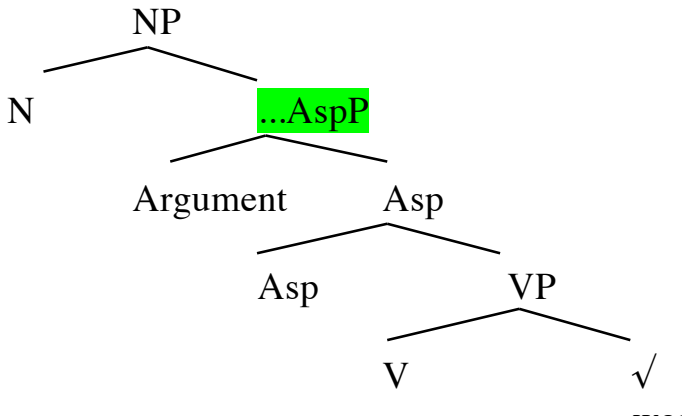

war

The exponent spells out the classifier plus a root; in this tree, by the Superset Principle, it only spells out the root. Given its lexical entry, it cannot spell out [V] (or the higher verbal projections). This means that $\mathrm{V}$ will have to be materialized by an overt verbalizer. This is what happens in Spanish: in order to build a verb from the noun guerra 'war', an overt verbalizer has to be used. This is due to the fact that V has to be spelled out.

$$
\begin{aligned}
& \text { guerr-e-a } \\
& \text { war-vbz-ThV } \\
& \text { 'make war' }
\end{aligned}
$$

Once a distinct exponent is introduced in $\mathrm{V}$, an overt nominalizer will be necessary to express a potential AS-nominal. 


\section{Conclusions}

To summarize, our proposal is that there are two classes of verb-related nouns in Spanish and English that share the same morphological make up, but involve different verbal structures. The first class of nouns, presented in (13) for Spanish, and represented in English by the class that includes walk, is built by nominalising a root. The second class of nouns, those in (14) for Spanish and including the class of attack in English, is built from a verbal structure that can include verbal functional projections that, in some cases, include the projection that introduces the external argument. This second class behaves like AS-nominals, while the first class are simple event nouns or R-nominals, depending on their conceptual entry. This class of ASnominals has a special morphological make-up because, we argued, the exponent that can materialize the verb is a portmanteau morpheme that can also lexicalize the nominalizer.

It is worth noticing that our account of these facts relied on the lexical entry of the exponents that spell out the roots and different formal features. No morphophonological idiosyncratic rules or zero affixes had to be used to capture the apparent exceptions to Grimshaw's (1990) generalization relating morphological marking and the AS- or R- nature of the nominals. We just had to propose different lexical entries for different exponents -something that they independently needed in their interaction with phrasal spell out and the Superset Principle. ${ }^{8}$

To conclude, there are some open issues that should be addressed in further research. One of them has to do with the technical implementation of phrasal spell out. There are different options in the literature to give an account of situations where one exponent spells out a series of heads: head-movement (Matushansky 2006), fusion as a post-syntactic operation (Halle \& Marantz 1993; Embick \& Noyer 2001), having lexical items correspond to subtrees (Starke 2009; McCawley 1968; Neeleman \& Szendröi 2007; Weerman \& Evers-Vermeul 2002; Caha 2009) or spanning (Ramchand 2008, Dékány 2012). The first approach cannot be adopted in our analysis, given the assumption that roots lack a grammatical category -which would make the fact that they have to move to check categorial features in the syntax surprising- but deciding between the three remaining approaches clearly requires more research. For our purposes, anyway, what is crucial is to show that the data can be captured if one exponent spells out several heads, and we hope to have provided enough evidence for that analysis.

Another open issue is, of course, extending this analysis to cases of apparent zero nominalizations from adjectives, like deliverable, or cases like delegate, where the noun expresses a participant. Even though we have suggested a possible reason why these cases are special (cf. footnote 2), it is obvious that much more should be said about them. However, we hope that at least for the cases discussed here we have managed to show that some zero nominalizations contain argument structure, and that they can be accounted for in an analysis that employs phrasal spell out.

\section{References}

\footnotetext{
As one anonymous reviewer points out, the Superset involves, in some sense, that some of the postsyntactic operations of Distributed Morphology would be part of the spell out procedure: ultimately, some of the nodes in the lexical entry of the exponent can be ignored. In Distributed Morphology, these postsyntactic operations would apply before spell out (Embick \& Noyer 2001): to account for these cases, it is conceivable that a post-syntactic obliteration operation (Arregi \& Nevins 2012) erases N from the ASnominal when that head is immediately adjacent to the exponent that spells out some roots, like attack. If additional exponents are between $\mathrm{N}$ and the root (ize, theme vowels, etc.), the operation does not apply. Deciding between the two procedures -syncretism resolved by an operation previous to spell out or by a spell out rule which is allowed to ignore material in the exponent- requires examining a wider set of data and languages, eventually, including also psycholinguistic evidence. Thus, I leave open the question of whether the solution proposed here is more economical than postulating a post-syntactic set of operation, pending further research.
} 
Acquaviva, P. 2009. Roots and Lexicality in Distributed Morphology. In: Galani, A., D. Redinger and N. Yeo (eds.) York-Essex Morphology Meeting 2, University of York, York, pp. 1-21.

Alexiadou, A. 2001. Functional structure in nominals: Nominalizations and ergativity, John Benjamins, Amsterdam.

Arad, M. 2003. Locality constraints on the interpretation of roots: the case of Hebrew denominal verbs. Natural Language and Linguistic Theory 21, 737-778.

Arad, M. 2005. Roots and Patterns: Hebrew Morpho-syntax. Springer, Dordrecht.

Aronoff, M. 1994. Morphology by itself: Stems and Inflectional classes. MIT Press, Cambridge (Mass.).

Arregi, K. \& A. Nevins. 2012. Morphotactics. Basque auxiliaries and the structure of spellout. Springer, Dordrecht.

Baker, M. C. 2003. Lexical categories, Cambridge University Press, Cambridge.

Baker. M. C. 2008. The syntax of agreement and concord. Cambridge University Press, Cambridge.

Bauer, L. 2001. Morphological productivity. Cambridge University Press, Cambridge.

Blevins, J. C. 2003. Stems and paradigms. Language 79, 737-767.

Borer, H. 1998. Passive without theta-grids. In: Lapointe, S., P. Farrell \& D. Brentari (Eds.) Morphology and its relation to phonology and syntax, CSLI, Stanford, pp. 60-99.

Borer, H. 1999. The form, the forming and the formation of nominals. Talk given at ZAS, Berlin.

Borer, H. 2003. Exo-skeletal vs. endo-skeletal explanations. In: Moore, J. and M. Polinsky (Eds.) The nature of explanation in linguistic theory, CSLI and University of Chicago Press, Chicago, pp. 31-67.

Borer, H. 2005a. In Name Only, vol.1 from The Exoskeletal Trilogy, Oxford University Press, Oxford.

Borer, H. 2005b. The Natural Course of Events, vol. 2 from The Exoskeletal Trilogy, Oxford Universty Press, Oxford.

Borer, H. 2009a. 'Roots and categories' ms, University of Southern California. Handout of keynote address to the Circle of Generative Grammar, University of the Basque Country, April 2009.

Borer, H. 2009b. 'Categorizing roots'. Handout of an invited talk, CASTL Colloquium, Troms $\varnothing$, University of Troms $\varnothing .15^{\text {th }}$ of October 2009.

Borer, H. 2012. In the event of a nominal. In: Everaert, M., M. Marelj \& T. Siloni (Eds.), The theta system, Oxford University Press, Oxford, pp. 103-150.

Bowers, J. 1993. The syntax of predication. Linguistic Inquiry 24, 591-656.

Caha, P. 2009. The Nanosyntax of Case, Ph.D. dissertation, CASTL, Universitetet i Troms $\varnothing$.

Clark, E. V. \& H. H. Clark. 1979. When nouns surface as verbs. Language 55, 767-811.

Condoravdi, C. 1989. Indefinite and generic pronouns. In: Fee, E. J., \& K. Hunt (Eds.) Proceedings of the Eight West Coast Conference on Formal Linguistics, CSLI, Stanford, pp. 71-85.

Corbett, G. 1991. Gender. Cambridge University Press, Cambridge.

Croft, W. 1991. Syntactic categories and grammatical relations: The cognitive organization of information. The University of Chicago Press, Chicago.

Dékány, É. 2012. A profile of the Hungarian DP: The interaction of lexicalization, agreement and linearization with the functional hierarchy. Doctoral dissertation, Universitet i Troms $\varnothing$.

Den Dikken, M. 2006. Relators and Linkers. MIT Press, Cambridge (Mass.).

Don, J. 1993. Conversion in Dutch. Doctoral dissertation, Utrecht University.

Don, J. 2004. Categories in the lexicon. Linguistics 42, 931-956.

Embick, D. 2000. Features, syntax and categories in the Latin perfect. Linguistic Inquiry 31, $185-230$. 
Embick, D. \& R. Noyer. 2001. Movement operations after syntax, Linguistic Inquiry 32, 555595.

Fábregas, A. 2005. The definition of the grammatical category in a syntactically-oriented morphology. Doctoral dissertation, Universidad Autónoma de Madrid.

Fábregas, A. 2009. An argument for phrasal spell out: indefinites and interrogatives in Spanish. In: Svenonius, P., G. Ramchand, M. Starke and K. T. Taraldsen (Eds.) Norlyd 36:1 . Special issue on Nanosyntax, Septentrio, Tromsø, pp. 129-168.

Grimshaw, J. 1990. Argument structure, MIT Press, Cambridge (Mass.).

Hale, K. \& S. J. Keyser. 2002. Prolegomenon to a theory of argument structure. MIT Press, Cambridge (Mass.).

Halle, M. 1992. Latvian declension. In: Booij, G. \& J. van der Marle (Eds.), Morphology Yearbook 1991, Kluwer, Dordrecht, pp. 33-47.

Halle, M. 1997. Distributed morphology: Impoverishment and Fission. In: B. Bruening, Y. Kang \& M. McGinnis (Eds.), MITWPL 30: Papers at the Interface, MIT, Cambridge (Mass.), pp. 425-449.

Halle, M. \& A. Marantz. 1993. Distributed Morphology and the Pieces of Inflection. In: Hale, K., \& S. J. Keyser (Eds.), The View from Building 20, MIT Press, Cambridge (Mass.), pp. 111-176.

Harley, H. 1995. Subjects, events and licensing. Doctoral dissertation, MIT.

Harley, H. and R. Noyer. 1998. 'Licensing in the non-lexicalist lexicon: nominalizations, Vocabulary Items and the Encyclopedia', in Heidi Harley (ed.), MIT Working Papers in Linguistics 32: Papers from the UPenn/MIT Roundtable on Argument Structure and Aspect, MIT, Cambridge (mass.), 119-137.

Harris, J. W. 1991. The exponence of gender in Spanish. Linguistic Inquiry 22, 27-62.

Jackendoff, R. 1975. Morphological and semantic regularities in the lexicon. Language 51, 639671.

Kempchinsky, P. 1987. The subjunctive disjoint reference effect. In: Neidle, C. \& R. NúñezCedeño (Eds.), Studies in Romance Linguistics, Foris, Dordrecht, pp. 123-140.

Kempchinsky, P. 2009. What can the subjunctive disjoint reference effect tell us about the subjunctive? Lingua 119, 1788-1810.

Kiparsky, P. 1982. Word-formation and the lexicon. In: Ingeman, F. (Ed.) Proceedings of the 1982 Mid-America Linguistic Conference, pp. 3-29.

Langacker, R. 1999. Foundations of Cognitive Grammar. Stanford University Press, Stanford.

Lebeaux, D. 2010. Where does binding theory apply? MIT Press, Cambridge (Mass.).

Lieber, R. 1981. Morphological conversion within a restricted theory of the lexicon. In: Moortgat, M., H. Hulst \& T. Hoekstra (Eds.), The scope of lexical rules. Foris, Dordrecth, pp. 161-200.

Lieber, R. 2005. English word-formation processes. In: Lieber, R. \& P. Stekauer (Eds.) Handbook of Word Formation, Springer, Dordrecht, pp. 375-429.

Marantz, A. 1997. No escape from syntax: Don't try morphological analysis in the privacy of your lexicon. In: Dimitriadis, A. et alii (Eds.), Proceedings of the $21^{\text {st }}$ Annual Penn Linguistics Colloquium. UPenn, pp. 201-225.

Marantz, A. 2001. Words. Unpublished manuscript, MIT.

Marchand, H. 1966. The categories and types of present-day English word-formation: a synchronic-diachronic approach. University of Alabama Press.

Mateu, J. 2002. Argument structure: Relational construal at the syntax-semantics interface. Doctoral dissertation. Universitat Autònoma de Barcelona.

Matushansky, O. 2006. Head movement in linguistic theory. Linguistic Inquiry 37, 69-109.

McCawley, J. 1968. 'Lexical insertion in a transformational grammar without deep structure', Papers from the Fourth Regional Meeting Chicago Linguistic Society, 71-81.

Neeleman, A. \& K. Szendröi. 2007. Radical pro-drop and the morphology of pronouns. Linguistic Inquiry 38, 671-714. 
Newmeyer, F. J. 2009. Current challenges to the lexicalist hypothesis. An overview and a critique. In: Lewis, W. D., S. Karimi, H. Harley and S. O. Farrar (Eds.), Time and again, John Benjamins, Amsterdam, 91-117.

Noyer, R. 1997. Features, positions and affixes in autonomous morphological structures. Garland Publishing, New York.

Oltra-Massuet, I. 1999. On the constituent structure of Catalan verbs. MIT Working Papers in Linguistics 33, 279-322.

Oltra-Massuet, I. and K. Arregi. 2005. Stress-by-structure in Spanish. Linguistic Inquiry 36, 4384.

Picallo, C. 1985. Opaque domains. Doctoral dissertation, City University New York.

RAE (Real Academia Española). 2009. Nueva gramática de la lengua española, Espasa, Madrid.

Ramchand, G. 2008. Verb Meaning and the Lexicon: A First Phase Syntax, Cambridge University Press, Cambridge.

Samek-Lodovici, V. 2003. The internal structure of arguments. Evidence from complex predicate formation in Italian. Natural Language and Linguistic Theory 21, 835-881.

Scalize, S. 1984. Generative Morphology. Foris, Dordrecht.

Sichel, I. 2009. New evidence for the structural realization of the implicit external argument in nominalizations. Linguistic Inquiry 40, 712-723.

Sleeman, P. \& A.-M. Brito. 2010. Aspect and argument structure of deverbal nominalizations: a split vP analysis. In: Alexiadou, A. \& M. Rathert (eds.), The syntax of nominalizations across languages and frameworks, Mouton de Gruyter, Berlin / New York, pp. 199-219.

Starke, M. 2005. Nanosyntax. Unpublished class lecture notes. Universitet i Troms $\varnothing$.

Starke, M. 2009. Nanosyntax: a short primer to a new approach to language. In: Svenonius, P., G. Ramchand, M. Starke \& K. T. Taraldsen (Eds.), Nordlyd 36.1, Special issue on Nanosyntax, Septentrio, Troms $\varnothing$, pp. 1-6.

Stump, G. 2001. Inflectional morphology: A theory of paradigm structure. Cambridge University Press, Cambridge.

Takamine, K. 2010. The postpositional hierarchy and its mapping to clause structure in Japanese. Doctoral dissertation, Universitet i Troms $\varnothing$.

Trommelen, M. 1989. Lettergreepstruktuur en woordkategorie. Die Nieuwe Taalgids 82, 64-77.

Weerman, F. \& J. Evers-Vermeul. 2002. Pronouns and Case, Lingua 112, 301-338.

Williams, E. 1981. Argument structure and morphology. The Linguistic Review 1, 81-114.

Williams, E. 2007. Dumping lexicalism. In: Ramchand, G. \& C. Reiss (Eds.), The Oxford Handbook of Linguistic Interfaces, Oxford University Press, Oxford, pp. 353-382. 